REVISTA DE DERECHO UNED, NÚM. 7, 2010

\title{
LA MEDIACIÓN FAMILIAR. ALGUNAS CONSIDERACIONES. PARTE II
}

\author{
Guillermo Darriba Fraga \\ Abogado, Master en Violencia de Género
}

Resumen: Considerando el derecho de todos los ciudadanos al acceso a la justicia como uno de los objetivos clave de la política de la Unión Europea, los organismos europeos han hecho una apuesta decidida por la implantación de la Mediación como un procedimiento llamado a desarrollar en un futuro no muy lejano, una auténtica revolución en orden a dotar de contenido aquel derecho.

Así, y con fundamento en este impulso de las instituciones europeas, han sido las distintas Comunidades Autónomas las que han dado un paso decisivo para implementar es sus territorios el procedimiento de la Mediación, con especial incidencia en el ámbito familiar.

No obstante el mandato de las instituciones europeas, el Estado no ha desarrollado todavía una ley estatal de Mediación, ley que sería deseable en orden a disponer unos criterios comunes y que, a su vez, establezca los márgenes de ésta institución, pues se corre el riesgo de deslegitimarla donde su inicio, por crear confusión y desconfianza en su aplicación tanto para los ciudadanos como para los operadores profesionales.

Abstract: Taking into account that the right of all the citizens to have access to justice is one of the key objectives of the European Union politics, European organisms have chosen to introduce Mediation as a procedure to develop in the near future, a large revolution in order to provide meaning to such a right.

Based on this impulse of the European institutions, the different Autonomous Communities gave a decisive step towards implementing their territories according to the procedure of Mediation, with a particular repercussion in the family environment. 
In spite of the European institutions mandate, the State has not developed any Mediation law yet, that would be desirable in order to offer common criteria as well as establishing the limits of such an institution, since there is a risk of delegitimizing it from its beginning as it creates confusion and mistrust in its application both towards citizens and professionals.

Palabras clave: Justicia privada, solución extrajudicial, resolución alternativa de litigios, método de gestión de conflictos, acceso a la justicia, cultura del acuerdo.

Key words: Private justice, out-of-court settlement, alternative dispute resolution, conflict management methods, access to justice, culture of agreement.

Sumario: I.- Introducción.-II. Tratamiento y Legislación en el ámbito europeo.-III. Tratamiento y legislación nacional.-IV. La Mediación.-IV.1. Concepto.-IV.2. Principios Rectores.-IV.3. Características.-IV.4. El Acuerdo.-IV.5. Ventajas de la Mediación.-V. Conclusiones. Bibliografía.

\section{INTRODUCCIÓN.}

Habiendo considerado como una de las causas probables del resurgimiento de las distintas modalidades de los denominados sistemas alternativos de resolución de conflictos ADR, o también denominadas modalidades de justicia privada ${ }^{1}$, una más rápida y eficaz respuesta al derecho de todos los ciudadanos al acceso a la justicia, y teniendo en cuenta que uno de los objetivos clave de la política de la Unión Europea para establecer un espacio de libertad, seguridad y justicia es mejorar precisamente ese acceso a la justicia, es por lo que la implantación y desarrollo de las ADR representa una prioridad política para las instituciones de la Unión Europea a las que incumbe promover y procurar el mejor entorno posible para el desarrollo de estas modalidades alternativas.

No obstante, hay que tener en cuenta que este interés por el desarrollo de las ADR, se produce como consecuencia de la toma de conciencia por parte de los organismos europeos, del nacimiento de nuevos o el resurgimiento de remodelados métodos de resolu-

${ }^{1}$ Libro Verde sobre modalidades alternativas de resolución de conflictos en el ámbito del derecho civil y mercantil, Bruselas, 19.04.2002 COM (2002) 196 final. Pág. 6. 
ción de conflictos, que vienen a satisfacer las demandas de una necesidad ciudadana de un mejor acceso no sólo a la administración de justicia, sino también al concepto superior que conlleva su aplicación.

Esta toma de conciencia por parte de las instituciones europeas ha llevado a las mismas a proponer diversos instrumentos en orden a proporcionar unos criterios de actuación, unos principios comunes, que no legislación propiamente dicha, en todo el ámbito comunitario para el desarrollo por parte de los Estados miembros de procedimientos alternativos de carácter extrajudicial.

\section{TRATAMIENTO Y LEGISLACIÓN DE LA MEDIACIÓN EN EL ÁMBITO EUROPEO}

Actualmente en el ámbito europeo se están desarrollando iniciativas a nivel legislativo fundamentalmente desde los organismos comunitarios, con el objetivo de que los Estados miembros tomen en consideración la mediación como un sistema plenamente válido para la resolución de conflictos, y a tal efecto son de destacar:

- La Recomendación N ${ }^{\circ}$ R (98) 1 del Comité de Ministros a los Estados miembros sobre la Mediación Familiar. (Aprobada por el Consejo de Ministros el 21 de enero de 1998).

- Directiva 2008/52/CE del Parlamento Europeo y del Consejo, de 21 de mayo de 2008 sobre ciertos aspectos de la mediación en asuntos civiles y mercantiles.

También a tener en cuenta, aún no siendo legislación propiamente dicha:

- El Libro Verde sobre las modalidades alternativas de solución de conflictos en el ámbito del Derecho civil y mercantil. Bruselas, abril 2002.

- La Propuesta de Directiva del Parlamento europeo y del Consejo sobre ciertos aspectos de la Mediación en asuntos civiles y mercantiles, presentada por la Comisión Europea el 22 de octubre de 2004 (COM 2004718 final).

Otra referencia en la materia la encontramos en el Reglamento 2201/2003 del Consejo, relativo a la competencia, el reconocimiento y ejecución de resoluciones judiciales en materia matrimonial y de responsabilidad parental, que en su artículo 55 de cooperación en ca- 
sos de responsabilidad parental, dispone: «...e) facilitar la celebración de acuerdos entre los titulares de la responsabilidad parental a través de la mediación o por otros medios... »

Uno de los objetivos de la política de la Unión Europea es mejorar el acceso a la justicia, para establecer un espacio de libertad, seguridad y justicia en el que los particulares no se vean impedidos ni disuadidos de ejercitar sus derechos por la complejidad o incompatibilidad de los sistemas legislativos y administrativos de los Estados miembros. ${ }^{2} Y$ en este sentido el concepto de acceso a la justicia debe incluir la promoción del acceso a procedimientos adecuados de resolución de conflictos, y no solamente el acceso al sistema judicial ${ }^{3}$.

$\mathrm{El}$ acceso a la justicia es un derecho fundamental consagrado en el artículo 6 del Convenio Europeo de la protección de los derechos humanos y libertades fundamentales.

Por su parte la Recomendación $\mathrm{N}^{\circ} \mathrm{R}$ (98) 1 del Comité de Ministros sobre la Mediación Familiar, recomienda a los gobiernos de los Estados miembros: Instituir o promover, o en su caso, reforzar la mediación familiar, así como adoptar o reforzar las medidas que consideren necesarias para la promoción y utilización de la mediación como medio apropiado de la resolución de conflictos familiares. Reconoce el propio Comité de Ministros la importancia de un método como la mediación para la resolución de conflictos familiares en especial los que se derivan de la separación y divorcio, basándose tanto en causas objetivas como subjetivas, entre las primeras destaca el creciente número de conflictos familiares, especialmente los que resultan de una separación o divorcio, las consecuencias de coste económico y social que los mismos representan para los Estados así como la internacionalización creciente de las relaciones familiares, entre los motivos subjetivos aducidos en la Recomendación destaca la importancia que la misma da a las consecuencias perjudiciales de los conflictos para los miembros de las familias y el aseguramiento en la protección del menor, con especial referencia a las materias de guarda y derecho de visita en los casos de separación o divorcio.

Del mismo modo la Propuesta de Directiva sobre Mediación en asuntos civiles y mercantiles (COM (2004) 718 final) en su Exposición de Motivos hace referencia a la consideración de la mediación como

${ }^{2}$ Así se establece en la Exposición de Motivos de la Propuesta de Directiva del Parlamento Europeo y del Consejo sobre ciertos aspectos de la mediación en asuntos civiles y mercantiles, presentada por la Comisión Europea el 22 de octubre de 2004 (COM (2004) 718 final). 
un método de resolución de conflictos que tiene valor propio y al que los ciudadanos y empresas debieran poder acceder fácilmente.

Es patente que los organismos comunitarios apuestan por la implantación de la mediación en los Estados miembros por los beneficios que la misma presenta como instrumento de resolución de conflictos, algunas de estas ventajas las enumera la propia Propuesta de Directiva en su Exposición de motivos: "una manera más rápida, simple y rentable de solucionar conflictos que permite tener en cuenta más aspectos de los intereses de las partes. Ello aumenta las posibilidades de alcanzar un acuerdo que respetarán voluntariamente y preserva una relación amistosa y sostenible entre ellos.»

En la misma línea se pronuncia finalmente la Directiva 2008/52/CE en su apartado (6) de su Considerando, al establecer que "La mediación puede dar una solución extrajudicial económica y rápida a conflictos en asuntos civiles y mercantiles mediante procedimientos adaptados a las necesidades de las partes. Es más probable que los acuerdos resultantes de la mediación se cumplan voluntariamente y también que preserven una relación amistosa y viable entre las partes».

En cuanto a la ventaja o beneficio que supondría el desarrollo de la mediación para la descongestión de los tribunales de justicia, pues al menos los asuntos que fuesen competencia o se resolviesen por mediación no se les presentarían pudiendo en consecuencia acortar los tiempos de resolución de los litigios así como el ahorro de fondos públicos, la Propuesta de Directiva hace referencia a la misma teniendo presente que si bien podría ser un aspecto positivo a tener en cuenta este no es uno de los objetivos a conseguir, fundamentalmente porque la Propuesta de Directiva lo que pretende es que la mediación tenga un valor propio como método de resolución de litigios «al que los ciudadanos y empresas pudieran acceder fácilmente y merece promoverse independientemente de su efecto de descarga de la presión sobre el sistema judicial». Así lo dispone finalmente la Directiva europea 2008/52/CE. ${ }^{4}$

${ }^{3}$ Así se establece en la Directiva 2008/52/CE del Parlamento Europeo y del Consejo, de 21 de mayo de 2008, sobre ciertos aspectos de la mediación en asuntos civiles y mercantiles. Considerando apartado (2): «El principio de acceso a la justicia es fundamental y, con vistas a facilitar y mejorar el acceso a la justicia, el Consejo Europeo en su reunión de Tampere de 15 y 16 de octubre de 1999, instó a los Estados miembros a que instauraran procedimientos alternativos de carácter extrajudicial».

${ }^{4}$ Directiva 2008/52/CE del Parlamento Europeo y del Consejo de 21 de mayo de 2008 sobre ciertos aspectos de la mediación en asuntos civiles y mercantiles, Art. 1.1.: «El objetivo de la presente Directiva es facilitar el acceso a modalidades alternativas de solución de conflictos y fomentar la resolución amistosa de litigios promoviendo el uso de la mediación y asegurando una relación equilibrada entre la mediación y el proceso judicial.» 


\section{TRATAMIENTO Y LEGISLACIÓN DE LA MEDIACIÓN EN EL ÁMBITO NACIONAL.}

Pese a que la citada Directiva europea en su art. 12 establece la obligación a los Estados miembros de poner en vigor las disposiciones legales, reglamentarias y administrativas necesarias para dar cumplimiento a lo ordenado en la misma antes del 21 de mayo de 2011, en nuestra legislación patria carecemos hasta la fecha de una Ley de Mediación a nivel estatal y han sido las Comunidades Autónomas las que han dado el primer paso a la hora de regular la mediación.

Esta impulso de la Mediación dada por los legisladores autonómicos, viene, como hemos visto, avalada desde la legislación comunitaria, cuyo objetivo es fomentar la resolución amistosa de litigios promoviendo el uso de la mediación, no obstante, no todas las Comunidades tienen potestad legislativa para regular materias de derecho civil. La Constitución Española en su artículo 149 que regula las competencias exclusivas del Estado, dispone que: "El Estado tiene competencia exclusiva sobre las siguientes materias:» en su apartado $8^{\circ}$ : "Legislación civil, sin perjuicio de la conservación, modificación y desarrollo por las Comunidades Autónomas de los derechos civiles, forales o especiales, alli donde existan. En todo caso, las reglas relativas a la aplicación y eficacia de las normas jurídicas, relaciones jurídico-civiles relativas a las formas del matrimonio, ordenación de los registros e instrumentos públicos, bases de las obligaciones contractuales, normas para resolver los conflictos de leyes $y$ determinación de las fuentes del Derecho, con respecto, en este último caso, a las normas de derecho foral o especial.»

De este modo tan sólo las Comunidades en donde existan derechos civiles, forales o especiales propios podrían haber regulado la institución de la mediación con fundamento constitucional en el artículo 149, sin embargo esto no ha sido así y las demás Comunidades que carecen de derecho propio han fundamentado su regulación en el artículo 148.1 de la Constitución que dispone: «Las Comunidades Autónomas podrán asumir competencias en las siguientes materias: $20^{\circ}$ Asistencia Social». Esto es, consideran la mediación como un servicio social.

La Leyes autonómicas promulgadas hasta la fecha en la materia son:

— En Cataluña, la Ley 1/2001, de 15 de marzo, de Mediación Familiar de Cataluña.

— En Galicia, la Ley 4/2001, de 31 de mayo, Reguladora de la Mediación Familiar. 
- En Valencia, la Ley 7/2001, de 26 de noviembre, Reguladora de la Mediación Familiar en el Ámbito de la Comunidad Valenciana. miliar.

- En Canarias, la Ley 15/2003, de 8 de abril, de la Mediación Fa-

— En Castilla y La Mancha, la Ley 4/2005, de 24 de mayo, del Servicio Social Especializado de Mediación Familiar.

- En Castilla y León, la Ley 1/2006, de 6 de abril, de Mediación Familiar de Castilla y León.

- En Baleares, la Ley 18/2006, de 22 de noviembre, de Mediación Familiar.

- En Madrid, la Ley 1/2007, de 21 de febrero, de Mediación Familiar de la Comunidad de Madrid.

- En Asturias, la Ley del Principado de Asturias 3/2007, de 23 de marzo, de Mediación Familiar.

— En el País Vasco, la Ley 1/2008, de 8 de febrero, de Mediación Familiar.

- Y por último, en Andalucía la Ley 1/2009, de 27 de febrero, reguladora de la Mediación Familiar en la Comunidad Autónoma de Andalucía.

todos los legisladores autonómicos españoles han efectuado un reconocimiento expreso a la eficacia de la mediación familiar en los conflictos familiares. Así la Ley catalana 1/2001 en su preámbulo refiere que «la mediación familiar ha sido una solución eficaz de los conflictos familiares, tanto desde el punto de vista de la prevención como de la resolución de estos». En la Ley gallega 4/2001, en su preámbulo menciona que «Este instrumento de mediación familiar...la efectividad real del mismo ha sido contrastada de modo suficiente en algunos ámbitos, revelándose como un instrumento eficaz de solución de las discordias entre esposos o pareja». La Ley valenciana 7/2001 también hace referencia a la eficacia de la mediación «La eficacia de la mediación familiar se vislumbra especialmente en los casos de crisis de convivencia». La Ley Canaria 15/2003, dispone que "La mediación familiar viene cobrando en la actualidad mucha relevancia como solución de los conflictos familiares y, con ello, como el método más efectivo para alcanzar la paz social». En el preámbulo de la Ley de Castilla la Mancha 4/2005, se la califica de «Un formidable y útil método de pacificación de los conflictos familiares, particularmente de los derivados de la ruptura de una pareja». Por su parte en 
el preámbulo de Ley de Castilla-León 1/2006, se dispone que «La mediación familiar se inserta como una fórmula adecuadamente contrastada para encauzar de forma óptima los conflictos familiares y, en especial, los de pareja».

Del mismo modo todas las Leyes autonómicas definen bien en su preámbulo, bien en su articulado lo que ha de entenderse por mediación así como sus características y los principios rectores de la misma, también se delimitan cuales han de ser los conflictos susceptibles de mediación en consideración a cada concreta ley, y así, de forma escueta la configura la recientemente aprobada ley andaluza en su exposición de motivos»Un procedimiento de gestión de conflictos en el que las partes enfrentadas acuerdan que una tercera persona cualificada, imparcial y neutral les ayude a alcanzar por sí mismas un acuerdo, que les permita resolver el conflicto que las enfrenta, sin necesidad de someterlo a una autoridad judicial».

En el ámbito del Estado, la primera ley que ha hecho referencia a la mediación ha sido la Ley Orgánica 1/2004, de 28 de diciembre, de Medidas de Protección Integral contra la Violencia de Género, en su artículo 44, en virtud del cual se adiciona un artículo 87 ter en la Ley Orgánica 6/1985, de 1 de julio, del Poder Judicial (LOPJ), con la siguiente redacción:»5. En todos estos casos está vedada la mediación». Ergo, viene a establecer, a sensu contrario, la posibilidad del mecanismo de la mediación.

No obstante, ha sido la Ley 15/2005, de 8 de julio, por la que de modifica el Código Civil y la Ley de Enjuiciamiento Civil en materia de separación y divorcio, la que introduce por vez primera en el ordenamiento jurídico de ámbito estatal una referencia positivista a la mediación familiar y así en la Exposición de Motivos de la Ley se indica literalmente: "...Las partes pueden pedir en cualquier momento al Juez la suspensión de las actuaciones judiciales para acudir a la mediación familiar y tratar de alcanzar una solución consensuada en los temas objeto del litigio.» Y en este sentido el apartado tres de la disposición final primera introduce una nueva regla $7^{\mathrm{a}} \mathrm{al}$ artículo 770 con la siguiente redacción: " $7^{a}$. Las partes de común acuerdo podrán solicitar la suspensión del proceso de conformidad con lo previsto en el artículo 19.4 de esta Ley, para someterse a mediación.» Por su parte, la Disposición final primera en su punto seis dispone: "Se modifica el apartado 2 del artículo 777, que queda redactado del siguiente modo:»2. Al escrito por el que se promueva el procedimiento deberá acompañarse...incluyendo en su caso, el acuerdo final alcanzado en el procedimiento de mediación familiar...", 
No obstante lo anterior, la referencia más importante de cara a una implementación de la mediación en nuestro ordenamiento mediante una regulación por ley estatal, aún cuando respecto al tiempo, incertus cuando, es la establecida en la Disposición final tercera de la referida Ley en la que literalmente indica: «El Gobierno remitirá a las Cortes un proyecto de ley sobre mediación basada en los principios establecidos en las disposiciones de la Unión Europea, y en todo caso en los de voluntariedad, imparcialidad, neutralidad y confidencialidad y en el respeto a los servicios de mediación creados por las Comunidades Autónomas.»

\section{LA MEDIACIÓN}

La participación o intervención de un tercero, generalmente un anciano respetable y respetado por su comunidad, al que consultaban para dirimir las controversias, es un método de resolución de conflictos tan antiguo como la propia formación de los primeros grupos humanos. La técnica de la mediación es usada en las culturas orientales desde hace milenios, por tanto la mediación no es un invento de nuestros tiempos ni es un recurso nuevo para la solución de conflictos.

Ahora bien, el modelo moderno de mediación nace en los Estados Unidos en los años setenta del siglo pasado, en concreto en la Universidad de Harvard como alternativa a la resolución de conflictos en el ámbito empresarial, con posterioridad se desarrolla en Canadá y en la década de los ochenta comienza su aplicación en el ámbito europeo principalmente en Inglaterra y Francia, también en Hispanoamérica la mediación tuvo un rápido despliegue destacando su avance en Argentina.

El desarrollo de la mediación hay que situarlo en el seno del movimiento de las ADR, Resolución Alternativa de Litigios, surgido como consecuencia, fundamentalmente, de la complejidad de los procesos judiciales y sobre todo de la ineficacia de los mismos para resolver la totalidad de los problemas planteados por los ciudadanos $\mathrm{y}$ de un cambio de conciencia y mentalidad en la sociedad que quiere participar cada vez más en la resolución de sus propios conflictos. Es precisamente en Estados Unidos donde surge un movimiento de pensamiento denominado "Critical Legal Studies»" que reivindica la

${ }^{5}$ Sobre la vinculación de los sistemas no jurisdiccionales al pensamiento denominado Critical legal studies, BARONA VILAR, Silvia en Solución extrajudicial de conflictos «Alternative Dispute Resolution» $(A D R)$ y derecho procesal, Tirant lo Blanch, Valencia 1999. Págs. 47 y ss. 
vuelta al realismo jurídico como contrapartida a la incapacidad del sistema jurídico vigente de dar soluciones efectivas a los litigios planteados. Y es que, ya sea por causas económicas, demográficas, o de adaptación a los avances sociales, el caso es que el sistema jurisdiccional es un mecanismo que deviene, cada vez más, ineficaz para otorgar tutela al ciudadano.

En este contexto surge la mediación como método de gestión y resolución de conflictos y que en el ámbito de la Familia, se desarrolla como un proceso caracterizado por el alto grado emocional de los implicados cuyos intereses confrontados están repletos de emotividad. En este ámbito de actuación, este proceso debe dirigirse hacia la consecución de un punto de encuentro lo más cercano posible a las distintas posturas divergentes, y para ello es esencial lograr el mayor grado de empatía posible, pues sólo así se conseguirán alcanzar los sacrificios de los intereses de cada parte necesarios y siendo indispensable además que sean las propias partes los que lo consigan, pues son ellas en definitiva quienes ostentan la responsabilidad, actuando el tercero en la discordia únicamente para posibilitar el acuerdo al que han de llegar.

Así, la mediación, el nuevo modelo de mediación, entendida como método para afrontar la resolución de conflictos, se aparece con una renovada carga de sugerencias y matices capaces de dar sentido y proyección a la realidad social que demanda un cambio en los modos de administrar justicia.

\section{IV.1. Concepto}

«La mediación es un proceso en virtud del cual un tercero, el mediador, ayuda a los participantes en una situación conflictiva a su resolución, que se expresa en un acuerdo consistente en una solución mutuamente aceptable y estructurada de manera que permita, de ser necesario, la continuidad de las relaciones entre las personas involucradas en el conflicto». ${ }^{6}$

Existen una gran cantidad de definiciones acerca de lo que debe entenderse por mediación, así nos encontramos con autores que la definen haciendo una descripción de los problemas que puede afrontar y una alusión a su existencia como método alternativo de solución a los conflictos, otros apuntan a principios que deben regir esta intervención

${ }^{6}$ HAYNES, John M. en Fundamentos de la Mediación Familiar Madrid, Ediciones Gaia, 1995. 
en la ruptura de pareja, incluso algunos autores aluden, dentro de sus caracteres como sistema, al restablecimiento de la comunicación interpartes como el elemento trascendente, de igual modo nuestros legisladores dotan a la mediación de múltiples axiomas dándole en cada una de ellas características comunes pero sin dotarlas de uniformidad.

Otros autores la definen como un método alternativo de resolución de conflictos y otros como un método de gestión de conflictos, Trinidad Bernal la define como una «técnica pacífica de resolver conflictos donde el protagonismo lo tienen las partes, cambiando el rol de los actores intervinientes en la situación conflictiva.» ${ }^{7}$

Así pues, puede apreciarse una evolución del concepto de mediación, en primer lugar se le consideró como un sistema alternativo de resolución de conflictos confrontado al sistema judicial, posteriormente se la ha conceptuado como sistema complementario, también como sistema independiente, incluso como sistema adecuado al judicial y actualmente como un sistema de gestión y, en su caso de resolución de conflictos y, dado que, aún cuando al final algunas mediaciones terminen sin acuerdo en los tribunales, el hecho de haber negociado previamente rebaja la tensión y mejora la comunicación inicial existente entre la pareja, se trata por tanto, de una gestión positiva, de este modo el actual perfil conceptual de la mediación podríamos resumirlo en un sistema de gestión positiva y de autocomposición de conflictos.

\section{IV.2. Principios Rectores}

La Mediación rige su funcionamiento por unos principios básicos que fundamentalmente informan la intervención del profesional mediador, además como sistema se caracteriza por una serie de notas que lo distinguen de los demás métodos de resolución de conflictos. Tanto unos como otros han sido y son discutidos y matizados.

Entre los principios esenciales del sistema podemos destacar:

\section{La voluntariedad.}

La mediación es un acto voluntario de las partes, las partes son libres en todo momento del proceso, tanto para iniciarlo, como para

\footnotetext{
${ }^{7}$ BERNAL SAMPER, Trinidad La Mediación una solución a los conflictos de pareja, op. cit. Pág.77.
} 
permanecer en él así como para finalizarlo, es decir cómo va a concluir. No obstante, la voluntariedad de la mediación es una característica referida fundamentalmente al resultado, pues la solución del conflicto ha de depender siempre de la voluntad de las partes, y nunca puede venir impuesta por un tercero, en otro caso estaríamos desnaturalizando la mediación.

En relación al inicio del proceso de mediación, dependiendo de su regulación en el ordenamiento esta puede ser preceptiva o facultativa para las partes. La Propuesta de Directiva del Parlamento Europeo y del Consejo sobre ciertos aspectos de la mediación en asuntos civiles y mercantiles (COM (2004) 718 final) contempla ambas modalidades (art. 3.2), pues se muestra respetuosa con aquellos ordenamientos nacionales que tengan implantada una mediación obligatoria, siempre y cuando no se impida el acceso al sistema judicial, aspecto este que ha sido asumido en su práctica literalidad en el art. 5.2 de la Directiva europea 2008/52/CE.

También La Recomendación $n^{\circ} \mathrm{R}$ (98) 1, del Comité de Ministros a los Estados miembros sobre la Mediación Familiar hace referencia a que la mediación no debe, en principio, ser obligatoria (apartado II a) y que los Estados son libres de organizar y poner en marcha la mediación de la forma que estimen apropiada (apartado II b).

En nuestra legislación autonómica se recoge la figura de manera prácticamente unánime en todas las leyes, en todas se hace referencia a la voluntariedad como principio informador tanto en los preámbulos como en su articulado y tanto respecto de las partes como de la persona mediadora. No obstante su carácter esencialmente voluntario y el hecho que la legislación incida en que son las partes las que decidirán libremente acogerse o no a la mediación, en los países con tradición mediadora, como Estados Unidos, su práctica ha derivado en otorgar a la misma, en determinados ámbitos, un carácter obligatorio. Sin embargo no parece que la obligatoriedad del instituto sea recomendable pues en ese caso se formalizaría y se convertiría en un mero trámite y en un presupuesto más de todo proceso.

Un ejemplo claro lo tenemos en nuestro Derecho histórico con la figura de la conciliación. La Ley de Enjuiciamiento Civil de 1881 confería a la conciliación pre-procesal un carácter preceptivo, antes de promover un juicio debía de intentarse la conciliación ante el juez competente (art. 460) y no se admitiría la demanda sino iba acompañada de una certificación de, al menos, haberse intentado el acto de conciliación (art.462). De este modo la conciliación se convirtió en un impedimento procesal previo al proceso. 
Finalmente, la Ley 34/1984, de 6 de agosto, de Reforma Urgente de la Ley de Enjuiciamiento Civil, confirió al acto de conciliación carácter meramente facultativo. Sin embargo, la única relevancia práctica del carácter voluntario otorgado a la conciliación ha sido que evita a las partes que tengan que cumplir con un trámite previo de acceso al proceso.

Es interesante en este sentido lo establecido en nuestra legislación autonómica, entre otras la Ley Gallega o la Ley Valenciana, en cuanto establecen que la autoridad judicial puede proponer a las partes la mediación durante el desarrollo de los procesos de separación, divorcio o nulidad, así los órganos jurisdiccionales pueden «aconsejar» esta opción a las partes ante su posible desconocimiento, indicando, a la vista del caso concreto sus posibles ventajas como vía previa y alternativa a la judicial, también el Protocolo para la implantación de la Mediación Familiar intrajudicial en los Juzgados y Tribunales que conocen de procesos de familia, del Consejo General del Poder Judicial, de mayo de 2008, hace especial hincapié en la necesidad de que fundamentalmente sean los jueces los que ilustren a las partes así como a sus representantes legales de los beneficios de la mediación y establece en la figura del juez «el elemento fundamental en la implantación de la mediación.... ${ }^{8}$ si ello se lleva a la práctica se fomentaría una cultura de la mediación que a la postre es lo que conlleva al buen uso y ejercicio de las instituciones.

En el mismo sentido se pronuncia en el ámbito comunitario la Directiva 2008/52/CE del Parlamento europeo y del Consejo sobre ciertos aspectos de la mediación en asuntos civiles y mercantiles, de 21 de mayo, que en su artículo 5.1 establece: «El órgano jurisdiccional que conozca de un asunto, cuando proceda y teniendo en cuenta todas las circunstancias del caso, podrá proponer a las partes que recurran a la mediación para solucionar el litigio.» Y aún va más allá tratando de desarrollar un conocimiento de la institución pues a continuación y en el mismo artículo dispone: "Asimismo el órgano jurisdiccional podrá pedir a las partes que asistan a una sesión informativa sobre el uso de la mediación, si se celebran tales sesiones y si son fácilmente accesibles».

8 «...los Jueces han de ejercer un rol muy importante en la implantación de la mediación ya que son ellos los que deben promover y facilitar de forma activa y comprometida cualquier iniciativa de mediación intrajudicial». Protocolo para la implantación de la Mediación Familiar intrajudicial en los Juzgados y Tribunales que conocen de procesos de familia del CGPJ de mayo de 2008, Pág. 7. 
Algunos autores han propuesto el establecimiento de un sistema institucional de mediación basado en el modelo argentino ${ }^{9}$, configurado como un sistema mixto de mediación. Este sistema se apoya en dos principios: la mediación previa obligatoria y la libertad de elección de los mediadores. Para que el sistema funcione se necesitan dos tipos de mediadores, en el sentido formal de estar o no registrados oficialmente, así se entenderá hecha una mediación y válido y eficaz el acuerdo alcanzado ante cualquiera de los dos tipos de mediador, pero para el supuesto de no haber alcanzado un acuerdo satisfactorio para ambas partes y la necesidad de acudir a la vía judicial sólo se entenderá cumplido el requisito de haber intentado un acuerdo si este se realizó ante un mediador inscrito en el registro oficial pertinente.

La voluntariedad manifestada libremente en la elección del mediador expresa el deseo de las partes de solucionar el conflicto, además las impregna de protagonismo, las convierte en autoras de su propia búsqueda de soluciones y las responsabiliza de los acuerdos a los que lleguen. No obstante, la voluntariedad no es privativa de las partes pues también afecta al mediador en un doble sentido, en primer lugar, porque la misma es fuente de la legitimación de su función y desempeño como tal, y en segundo lugar el mediador puede y debe suspender la mediación cuando lo considere oportuno de acuerdo con lo dispuesto en la legislación en vigor y en su lex artis.

\section{La Imparcialidad.}

Es la cualidad del mediador de no tomar partido por ninguna de las partes del conflicto, siendo objetivo en el tratamiento de la cuestión, equilibrando el tiempo y la atención que ambas partes necesiten. La imparcialidad es un hecho objetivo, no actuar ni a favor ni en contra de cualquiera de las partes, o como dice Javier Escrivá, «Más bien (el mediador) está en contra de los dos $»^{10}$. El mediador debe mantenerse en la distancia justa.

\footnotetext{
${ }^{9}$ Así LANDETE CASAS, José, en «Aspectos generales sobre la mediación y el mediador» Revista Internauta de Práctica Jurídica, núm. 2 mayo-agosto 1999. Según este autor se previenen con este sistema dos peligros: al ser obligatoria impide que la eviten los litigantes y se respeta la libertad de los mismos a la hora de elegir el mediador.

${ }^{10}$ ESCRIVÁ-IVARS, Javier op. cit. Pág. 135. «(El mediador) está en contra de todas aquellas actitudes que puedan ser lesivas, injustas o vejatorias para el otro o los menores.»
} 
Trinidad Bernal, ${ }^{11}$ considera la imparcialidad una de las cualidades más importantes de un mediador, manteniendo una posición intermedia entre ambas partes, dando el debido peso a cada punto de vista.

Hay elementos objetivos que rompen la imparcialidad del mediador, como son relaciones de amistad, de parentesco o bien de enemistad manifiesta o relaciones de dependencia personal o profesional o intereses contrapuestos con alguna de las partes.

La Recomendación $\mathrm{N}^{\circ} \mathrm{R}$ (98)1 del Comité de ministros a los Estados miembros sobre la mediación familiar, recoge la imparcialidad como un principio del proceso de mediación.

La ley Catalana 1/2001 de Mediación recoge el principio de imparcialidad como un deber del mediador en su artículo 12 al disponer: "La persona mediadora tiene el deber de la imparcialidad y en consecuencia, ha de ayudar a los participantes a alcanzar los acuerdos pertinentes sin imponer ninguna solución ni medida concreta ni tomar parte.» También la Ley Canaria 15/2003 de Mediación establece la imparcialidad como un deber en su artículo 8: «El mediador familiar a lo largo de toda su actuación debe...Mantener la imparcialidad no pudiendo tener designio anticipado o prevención a favor o en contra de alguna de las partes.»

Para garantizar la imparcialidad del mediador la Ley 4/2005 de Castilla-La mancha establece en su artículo 12 las causas de abstención que no son sino los elementos objetivos antes aludidos, del mismo modo se regulan también estas causas en la Ley Vasca 1/2008 en su artículo 14.2.

\section{La neutralidad.}

Es la característica del mediador que más confusión plantea por su proximidad con la imparcialidad, así como ésta hace referencia a la posición que ocupa el mediador respeto de las partes del conflicto, la neutralidad hace referencia a la actuación del mediador en el proceso y en la resolución y adopción de soluciones al mismo. La neutralidad hace referencia a los propios sentimientos y emociones del mediador. Es un hecho subjetivo, pues el mediador debe actuar con objetividad en el caso concreto, por ello es fundamental que el mediador no intente dirigir las opiniones de las partes ni las soluciones

${ }^{11}$ BERNAL SAMPER, Trinidad. op. cit. Pág. 68. 
a adoptar conforme a su escala de valores. Es más, este principio hace referencia al trabajo que el mediador debe realizar no sólo en relación con las partes, sino también frente a si mismo ${ }^{12}$. La influencia de la persona mediadora es inevitable por la propia naturaleza del proceso, pues se produce una interacción entre personas y en este proceso relacional las orientaciones del mediador por muy neutrales que se pretendan son portadoras de una ideología, de unos sentimientos, de unas creencias, de unos ideales, de unos principios y de unos valores que van a modular en mayor o menor medida toda implicación en el procedimiento mediador. Por ello habrá que especificar y diferenciar las formas aceptables de influencia del mediador por ser inevitables y formar parte del rol de mediador de aquellas otras que conllevan problemas y que deben ser inaceptables.

La neutralidad del mediador no debe confundirse con pasividad o dejadez, muy al contrario el mediador debe actuar activamente en la gestión del proceso de mediación, por tanto la neutralidad del mediador no es equivalente a remisión y falta de implicación. Un mediador no es neutral si con su actitud se adapta, sin criterio, a todas las sugerencias que hagan las partes.

Del mismo modo que respecto de la imparcialidad, la Recomendación Comunitaria $\mathrm{N}^{\mathrm{o}} \mathrm{R}$ (98) 1 reconoce como un principio a respetar en el proceso de mediación el de la neutralidad.

La ley Gallega 4/2001 de Mediación recoge este principio en su artículo 8.2, distinguiendo entre imparcialidad y neutralidad, así dispone que: "El procedimiento de mediación habrá de desarrollarse conforme a los postulados de imparcialidad y neutralidad de la persona mediadora, debiendo quedar garantizado que ésta respetará los puntos de vista de las partes y preservará su igualdad en la negociación, absteniéndose así mismo de promover actuaciones que comprometan su necesaria neutralidad.» Por su parte la Ley 1/2006 de Castilla y León si bien diferencia entre imparcialidad y neutralidad, no llega a definirlas y las regula como deberes de la persona mediadora en su artículo 10.1, del mismo modo la Ley Valenciana regula la neutralidad como deber del mediador en su artículo 9.g. si bien hace distinción entre imparcialidad y neutralidad en el preámbulo de la Ley relacionándolas como características independientes.

12 ESCRIVÁ-IVARS, Javier, op.cit. Pág.136. Para este autor: «Las dificultades del proceso para el mediador aumentan cuando se analizan los elementos de la culpabilidad. Ignorar por completo la culpabilidad significa confirmar que no hay nadie responsable. Lo ordinario es que ambas partes lo sean aunque con intensidad diferente». 


\section{La Confidencialidad.}

Es uno de los principios rectores clave del proceso de mediación, pero a diferencia de los anteriores no se trata de un principio absoluto toda vez que admite gradaciones por las respectivas legislaciones que regulan la mediación. Así la Recomendación Comunitaria $\mathrm{N}^{\circ}$ (98) 1, establece en su apartado III.VI que: «Las discusiones que tienen lugar durante la mediación son confidenciales y no pueden ser posteriormente utilizadas, salvo acuerdo de las partes o en el caso de estar permitido por el derecho nacional.» Además de un principio básico a observar, es una consecuencia lógica del tratamiento que se ha de dar a los conflictos familiares pues un contexto privado y sin publicidad favorece la resolución de los mismos y genera confianza en las partes. Por consiguiente la confidencialidad implica que la mediación ha de llevarse a cabo en privado y, por el deber de secreto de la información obtenida durante el proceso, esta no podrá ser revelada ni por el mediador ni por las partes. Debido a ello, las partes han de renunciar a proponer al mediador como testigo o perito en cualquier procedimiento que afecte al objeto de la mediación. Por otra parte, y como consecuencia de la relatividad de la confidencialidad se establece la obligación al mediador de revelar aquella información que hubiere obtenido, cuando a través de la misma se proteja el superior interés de un menor o si existieran indicios de criminalidad.

Esta cuestión de la confidencialidad afecta fundamentalmente al supuesto que las partes no hubiesen alcanzado un acuerdo y resolviesen acudir a la vía judicial o ya estando en ella ésta estuviese en suspenso en espera de lo que aconteciese en el proceso de mediación.

En estas circunstancias, debe evitarse que puedan utilizarse en el proceso las informaciones obtenidas de la otra parte en la mediación, y ello con el objetivo fundamental de preservar la imparcialidad del juez, que ha de alcanzar su convicción sobre lo alegado y probado en el acto del juicio, sin que puedan admitirse lo afirmado extrajudicialmente por cada parte en el proceso de mediación.

En este sentido y con el objetivo de garantizar la confidencialidad en todo proceso judicial posterior, la Propuesta de Directiva del Parlamento Europeo y del Consejo sobre ciertos aspectos de la mediación en asuntos civiles y mercantiles (COM (2004) 718 final), dedica un extenso y detallado artículo 6 a regular la admisibilidad en los procesos judiciales de las pruebas que tuvieran su origen en procesos de mediación, estableciendo al efecto una prohibición probatoria absoluta, si bien relacionada con determinados y tasados aspectos, de 
dar testimonio ni presentar pruebas en procesos judiciales civiles a los mediadores o personas implicadas en el proceso de mediación, finalmente la Directiva 2008/52/CE del Parlamento europeo y del Consejo sobre ciertos aspectos de la Mediación en asuntos civiles y mercantiles, en su art. 7 establece una dispensa a la obligación a declarar en un proceso judicial civil o mercantil y la amplía, respecto de la Propuesta, al arbitraje. Dispensa para la cual y al igual que lo establecido en la Propuesta de Directiva se establecen tres excepciones: Salvo acuerdo contrario de las partes, cuando sea necesario por razones de orden público y en particular la protección del menor o la prevención de daños a la integridad física o psíquica de las personas y, cuando el conocimiento del contenido del acuerdo resultante de la mediación sea necesario para aplicar o ejecutar dicho acuerdo.

En nuestra legislación autonómica, la Ley Catalana 1/2001 de Mediación, regula y define el principio de confidencialidad en su artículo 13, otorgándole el carácter de reservado a las actas que se elaboran en el proceso de mediación y establece la obligación de las partes a mantener el secreto de lo deliberado, del mismo modo establece las excepciones a este principio entre las que se encuentra la excepción a la confidencialidad cuando comporte una amenaza para la vida o la seguridad física y psíquica de una persona, en tal sentido, eleva la ley esta excepción a deber del mediador en el artículo 19. d) al disponer que «la persona mediadora ha de prestar una atención particular a cualquier signo de violencia doméstica, física o psíquica, entre las partes.»

Por su parte la Ley Gallega 4/2000 de Mediación Familiar, hace referencia a la confidencialidad y al secreto en el artículo 8.1 y los desarrolla normativamente en el artículo 11 en donde la confidencialidad queda configurada como un deber de la persona mediadora y de las partes, en su apartado 2 se establecen las excepciones, siendo el tenor literal de este apartado el siguiente:

"Se exceptúan de lo dispuesto en el apartado anterior los siguientes casos:

a) la información relativa a un procedimiento de mediación en curso requerida por el juez.

b) Toda información requerida por el Ministerio Fiscal en el ejercicio de sus funciones.

c) La consulta de los datos personalizados para fines estadisticos.» 
Si bien cualquiera de estas excepciones reguladas en el art.11.2, no entran en contradicción con lo estipulado en la normativa comunitaria, el tratamiento que la ley gallega da a la confidencialidad no es la más apropiada para generar confianza en este método de gestión positiva y resolución de conflictos por parte de los ciudadanos.

Así con la primera excepción, se rompe el círculo de privacidad y de relación cuasi-secreta que debe establecerse entre las partes y su mediador si cualquier juez, pues no se determina quien, y por cualquier razón para solicitar la información, son razones válidas para romper este principio fundamental. En un esfuerzo de interpretación literal colmado de buena fe, se puede presuponer que se trate del juez que esté conociendo el asunto, si estamos en un supuesto de mediación intrajudicial.

La segunda excepción, el requerimiento del Ministerio Fiscal quiebra definitivamente la confidencialidad, pues no se puede obviar que cualquier parte puede solicitar la intervención del Ministerio Fiscal.

Asimismo la posibilidad de consulta de los datos personalizados para fines estadísticos choca con lo establecido en las otras leyes autonómicas ${ }^{13}$, así como con la legislación estatal relativa a la protección de datos de carácter personal.

\section{El carácter personalísimo}

Este carácter del proceso de mediación puede deducirse de lo ya expuesto.

Y así, las partes deben asistir personalmente a las reuniones, no cabe la actuación de representantes o delegados ni de intermedia$\operatorname{rios}^{14}$, pues son los propios interesados los que han de resolver sus problemas y solo ellos saben donde anidan, de igual modo impregna

${ }^{13}$ Así la Ley del Principado de Asturias 3/2007, de 23 de marzo, de Mediación Familiar, en su artículo 7, dedicado a regular la Confidencialidad establece como excepción a dicho principio: «3. No está sujeta al principio de confidencialidad la información obtenida que: a) No sea personalizada y se utilice para fines estadísticos, de formación o investigación.» En el mismo sentido legisla la Ley 1/2007, de 21 de febrero, de Mediación Familiar de la Comunidad de Madrid, y así en su art. 18.4 establece que "No están sujetos al deber de confidencialidad los siguientes casos: a) La consulta de los datos no personalizados, para fines estadísticos o de investigación, respetándose el anonimato de los usuarios del servicio.»

${ }^{14}$ GARCÍA GARCÍA, Lucía en Mediación Familiar. Prevención y alternativa al litigio en los conflictos familiares Madrid, Dykinson 2003 Pág.146. 
este carácter a la figura del mediador, pues no es factible el cambiar de persona mediadora en cada sesión. En el supuesto de que el mediador proponga la intervención de otras personas en las reuniones, habrán de ser aceptadas por las partes. La Ley Valenciana 7/2001 de Mediación, lo regula expresamente en su artículo 15, también la Ley de Baleares 18/2006 en su artículo 17.1.

\section{3. Características del Sistema.}

Junto a los principios anteriormente desarrollados, y tal como hemos venido sosteniendo a largo del presente trabajo, la mediación como sistema se define a sí misma por una serie de caracteres sin los cuales perdería su identidad, no obstante algunos no son pacíficos, son discutidos o al menos matizados.

La mediación se encuentra incluida entre los medios autocompositivos de solución de controversias, entendiendo por autocomposición aquellos métodos donde las propias partes ponen fin al conflicto intersubjetivo de intereses a través del acuerdo de voluntades. Dentro de esta categoría de la autocomposición pertenecen también la renuncia del actor o el desistimiento del proceso, el allanamiento del demandado, la transacción entre las partes y la conciliación. Característica común a todos lo medios es el mayor o menor protagonismo de las partes en el acuerdo que ha de poner fin a la disputa, pero lo que caracteriza fundamentalmente a la mediación respecto de los demás medios de autocomposición, es la intervención de un tercero y sobre todo la forma de esa intervención. Una intervención reglada y delimitada, que no obstante, no ha de guardar ningún rigor formal o solemne y que dota de singularidad a la mediación diferenciándola de otras figuras afines. Esta intervención de un tercero difiere para algunos autores y así configuran la mediación como un método heterocompositivo ${ }^{15}$.

Otra de las características delimitadoras de la mediación es la conceptualización de la misma como un método alternativo, fundamentalmente al sistema judicial, en este sentido, la mayoría de las actuales Leyes autonómicas que regulan esta figura la definen como

${ }^{15}$ Entre otros LORCA NAVARRETE, Antonio María en La Regulación de la Separación y el Divorcio en la nueva Ley de divorcio de 2005 con especial referencia a la Mediación Familiar Pág. 113, dice este autor: «La mediación se conceptúa como medio heterocompositivo alternativo. La elección de la mediación familiar como instituto heterocompositivo alternativo para resolver una situación objetiva de crisis familiar, se justifica en los mismos criterios que permiten optar también a favor del arbitraje». 
un método extrajudicial de resolución de conflictos, así la Ley valenciana, la Ley asturiana o la Ley canaria, otras por el contrario la señalan, como la Ley catalana en su preámbulo, como «un método de resolución de conflictos...para evitar la apertura de procedimientos judiciales de carácter contencioso y poner fin a los ya iniciados o reducir su alcance». En el mismo sentido se pronuncia también la Ley gallega en su preámbulo. Algunos autores consideran la mediación no como una alternativa al proceso judicial sino como un complemento o una ayuda o auxilio al mismo, toda vez que aun cuando se desarrolla en un ámbito extrajudicial, ya sea antes de iniciado un proceso o con posterioridad al mismo, es el órgano jurisdiccional el que tiene la última palabra sobre el acuerdo alcanzado para dotarle de validez erga ommes.

Esto es considerando la mediación desde la perspectiva de método de resolución de conflictos, pero como anteriormente se apuntaba, una de las causas del desarrollo de los métodos alternativos de resolución de conflictos es que estas técnicas constituyen una respuesta eficaz al acceso a la justicia de los ciudadanos, por tanto desde la óptica de un mejor acceso a la justicia, estas técnicas, entre las que se encuentra la mediación, no deberían considerarse métodos alternativos ni siquiera complementarios al judicial, sino medios independientes de acceso a la justicia cuyo fundamento último se encuentra en la libertad de decisión de los ciudadanos.

Este es precisamente uno de los objetivos de la Propuesta de directiva del Parlamento Europeo y del Consejo sobre ciertos aspectos de la mediación en asuntos civiles y mercantiles COM (2004) 718 final, que en su Exposición de Motivos dispone: "La Comisión no considera a la mediación como una alternativa a los procesos judiciales, sino como uno de los diversos métodos de resolución de litigios disponibles en una sociedad moderna» (apartado 1.1.4).

No obstante la vigente Directiva 2008/52/CE, de 21 de mayo de 2008, del Parlamento Europeo y del Consejo, no se hace eco de este espíritu definidor de la mediación toda vez que la misma la configura en diversos apartados como método alternativo al sistema judi$\mathrm{cial}^{16}$, y así en su art. 1 en el que define la finalidad y ámbito de apli-

${ }^{16}$ En el Considerando apartado (2): «...El Consejo Europeo...instó a los Estados miembros a que instauraran procedimientos alternativos de carácter extrajudicial.» Apartado (19): «La mediación no debe considerarse como una alternativa peor que el proceso judicial por el hecho de que el cumplimiento del acuerdo resultante de la mediación dependa de la buena voluntad de las partes»Directiva 2008/52/CE, de 21 de mayo de 2008, del Parlamento europeo y del Consejo sobre ciertos aspectos de la Mediación en asuntos civiles y mercantiles. 
cación de la directiva, establece que: "El objetivo de la presente Directiva es facilitar el acceso a modalidades alternativas de solución de conflictos y fomentar la resolución amistosa de litigios promoviendo el uso de la mediación y asegurando una relación equilibrada entre la mediación y el proceso judicial».

Algunos autores consideran también características propias de la mediación, la flexibilidad y la informalidad del proceso, si bien es cierto que la mediación, como contraposición al proceso judicial que es absolutamente rígido en las formas, tiempos y procedimientos, es menos informal y más flexible en sus formalidades, sin embargo, como todo método que responde a una serie de pautas y modelos establecidos, dependiendo de la escuela a seguir, y siendo una negociación dirigida, habrán de plantearse unas reglas de obligado acatamiento por todos los intervinientes, pero como ya se ha apuntado, ha de huir de toda solemnidad en las formas para no perder ni un ápice de su esencia.

No obstante lo anterior, las características de la mediación se pueden refundir en dos aspectos esenciales de la misma, su objetivo y el modo en que este se alcanza. El objetivo último de la mediación es el acuerdo inter-partes que evita o pone fin a un litigio entre ellas, lo que singulariza ese acuerdo o su intento por alcanzarlo, es que en su consecución participa un tercero imparcial que actúa como mediador, con todo lo que ello representa, tratando de acercar las posturas enfrentadas de las partes.

\section{IV.4. El Acuerdo}

La finalidad de toda negociación es lograr un pacto que satisfaga a las partes negociadoras, por consiguiente, en la mediación este pacto se alcanza cuando las propias partes en conflicto logran llegar a un compromiso satisfactorio para ambas. Ahora bien, en un principio este arreglo sólo será eficaz, sin perjuicio de la eficacia interpartes, si el ordenamiento jurídico le confiere tal propiedad, y para ello es necesario dotarle de reconocimiento, validez y eficacia ergaomnes.

Si bien como apunta el profesor Lasarte ${ }^{17}$ los acuerdos familiares en los que la autonomía privada desempeña una cierta relevancia no

${ }^{17}$ LASARTE ÁlvareZ, Carlos Derecho de Familia, Principios de Derecho Civil, Tomo VI, $6^{\text {a }}$ edición. Madrid, Marcial-Pons, 2007, Pág.13. 
pueden englobarse conceptualmente bajo el paraguas teórico del negocio jurídico de Derecho de Familia, bien puede parecer que la culminación natural de toda mediación es el contrato de transacción ${ }^{18}$. Este está contemplado en nuestro ordenamiento en el artículo 1809 del Código Civil que dispone:"La transacción es un contrato por el cual las partes, dando, prometiendo o reteniendo cada una alguna cosa, evitan la provocación de un pleito o ponen término al que habían comenzado.»De dicha definición se traduce que la transacción, consiste básicamente en un arreglo o en un acuerdo que evite la intervención judicial y que son las propias partes interesadas quienes llegan a un pacto, convenio o acuerdo que dirime sus controversias. Dicho pacto tiene carácter contractual, así lo dispone el propio artículo 1809 del CC, no obstante, la jurisprudencia del Tribunal Supremo ${ }^{19}$ ha resaltado la necesaria concurrencia de los requisitos propios de dicho contrato que vendrían representados por: La existencia de controversia entre las partes, la voluntad de las mismas de poner fin a la situación conflictiva y una reciprocidad de las concesiones acordadas. En cuanto a esta reciprocidad: "Las reciprocas concesiones por parte de los interesados, (han de ser) de forma que sufran algún sacrificio de modo definitivo y no provisional» ${ }^{20}$.

En definitiva, la transacción se traduce en un acuerdo de voluntades por el que se compone la controversia entre partes y en este sentido, la transacción vendría a ser el resultado positivo de la mediación, pero sus efectos, son los derivados del deber de cumplimiento que pueden las partes exigirse recíprocamente mientras subsiste su vigencia, y es inoperante, en principio, respecto de terceros.

Ahora bien, en la mediación no todo es negociable, los acuerdos han de referirse a materias sobre las que las partes tengan poder de disposición y así, son límites propios a la autonomía de la voluntad de las partes las materias que afectan a la ley, la moral y el orden público y el propio Código Civil establece en su artículo 1814 que: "No se puede transigir sobre el estado civil de las personas, ni sobre cuestiones matrimoniales, ni sobre alimentos futuro». En relación a las cuestiones matrimoniales y a pesar del carácter absoluto de la prohibición, será posible transigir sobre los aspectos puramente patrimoniales del matrimonio, como también desde la Ley 30/1981,

${ }^{18}$ LANDETE CASAS, José en «Aspectos generales de la Mediación».op.cit.

${ }^{19}$ Entre otras, la STS de 27 de noviembre de 1987. Ponente: Gumersindo Burgos Pérez de Andrade.

${ }^{20}$ Fundamento de Derecho sexto STS Sala de lo Civil de 27 de noviembre de 1987. 
de 7 de julio, por la que se modifica la regulación del matrimonio en el Código Civil y se determina el procedimiento a seguir en las causas de nulidad, separación y divorcio (Ley del Divorcio), sobre algunos aspectos personales.

No hay que obviar que el acuerdo de mediación nace, con ayuda del mediador, de las propias partes en conflicto, es por ello que la figura del mediador es fundamental en su consecución pues en definitiva es el encargado de evitar que este se encuentre viciado por alguna causa.

Una vez finalizada la mediación si esta llega a buen puerto con la consecución de un acuerdo, las partes firmarán el acta de mediación donde se recogen los términos del mismo y, su cumplimiento dependerá exclusivamente de la voluntad de las partes, por tanto, aunque el acuerdo sea válido puede encontrarse con importantes obstáculos para su plena eficacia, de ahí la necesidad de su legalización definitiva que la hará ejecutable y oponible a terceros, ello se consigue con su homologación judicial, a través del correspondiente procedimiento judicial, si bien una alternativa práctica es su homologación elevando el acuerdo a documento público lo que se llevará a cabo por un notario, para su inscripción, si procede, en el correspondiente registro público. Dispone el artículo 1816 del Código Civil: "La transacción tiene para las partes la autoridad de la cosa juzgada; pero no procederá la vía de apremio sino tratándose del cumplimiento de la transacción judicial».

\section{5. Ventajas de la Mediación}

La mediación, por los principios que la conforman y los caracteres que la definen, presenta respecto de los demás procedimientos de resolución de conflictos, especialmente el judicial, una serie de ventajas que ha hecho que la propia Comisión Europea en su Propuesta de Directiva a los Estados miembros sobre la mediación, ya citada, aludiera a los beneficios que como mecanismo de resolución de conflictos presenta, así en apartado 1.1.3 de la Exposición de Motivos expone:»La utilidad de ampliar el recurso a la mediación la constituyen esencialmente las ventajas del propio mecanismo de solución de litigios: una manera más rápida, simple y rentable de solucionar conflictos que permite tener en cuenta más aspectos de los intereses de las partes.»

Ventajas todas ellas a las que también hace referencia la Directiva 2008/52/CE, y así en el Considerando apartado (6) establece que:»La 
mediación puede dar una solución extrajudicial económica y rápida a conflictos en asuntos civiles y mercantiles mediante procedimientos adaptados a las necesidades de las partes.»

En efecto, la mediación ofrece en sí misma grandes ventajas:

- Ahorra tiempo, la saturación de los órganos jurisdiccionales lleva a que determinados casos se eternicen, además las partes pueden limitar el tiempo que puede durar la mediación por lo que se convierte en un mecanismo más rápido de solución de conflictos que la jurisdicción.

- Descongestiona a los juzgados y tribunales de justicia ya que muchos asuntos son susceptibles de solución sin necesidad de que estos entren a conocer del fondo del asunto.

- Resulta generalmente una medida más económica que la vía judicial.

- Aumenta la responsabilidad de la partes, al dotarlas de protagonismo en la resolución de sus conflictos.

- En su caso, minimiza en los hijos los problemas derivados de la separación o divorcio, evitándoles culpabilidades, protagonismos y manipulaciones.

- Los acuerdos son más duraderos, pues como consecuencia de lo anterior, las partes se esfuerzan más en mantenerlos en el tiempo y cumplirlos adecuadamente.

- Mantiene relaciones. Hay conflictos, especialmente los generados en los supuestos de separación o divorcio, en que las partes, especialmente si hay hijos, necesitan seguir manteniendo la relación y un esquema de soluciones en el que se fomenta la dicotomía ganador-perdedor, haría complicado el mantenimiento de una mínima relación. Con la mediación esta relación puede mantenerse porque se fomenta la cultura del acuerdo.

- Se producen soluciones más satisfactorias. Al ser las soluciones consensuadas y buscadas por las propias partes éstas se implican más en su desarrollo y efectividad al contrario de lo que ocurre con la solución aportada por un juez o tribunal la cual es susceptible de ser percibida como injusta.

- Aumenta la creatividad de los acuerdos. Cada acuerdo ha de responder a la casuística planteada, cada solución es única. Como consecuencia de lo anterior cabe la posibilidad de que se 
generen alternativas más flexibles y viables que se adapten mejor a las necesidades particulares de las partes, y

- Se produce un «denteroaprendizaje ${ }^{21}$.Las personas al solucionar un conflicto, pueden adquirir capacidades para solucionar otros futuros conflictos de forma autónoma.

\section{Conclusiones}

Si tenemos en consideración que el grado de civilización de una sociedad no guarda relación ni se mide por la mayor o menor cantidad de conflictos que tenga, sino con el modo como estos son manejados, afrontados y resueltos, habremos de concluir que con la Mediación, en tanto en cuanto, método de gestión positivo y resolución de conflictos aplicado al ámbito familiar y en particular al de la pareja en proceso de disolución, configurada ésta como el epicentro de ordenación de la sociedad actual, alcanzamos cotas de autonomía y libertad individual hasta entonces no alcanzadas en la resolución de los problemas que acucian, como sociedad, el ámbito más íntimo de la misma.

En cuanto a las conclusiones que podemos resaltar de lo hasta aquí expuesto, a las que habría que añadir las ventajas enumeradas, podemos destacar las siguientes

- Primera. Debido al resurgimiento de métodos de gestión y resolución de conflictos distintos al judicial, las instituciones europeas están desarrollando iniciativas a nivel legislativo, con el objetivo de que los Estados miembros tomen en consideración la mediación como un sistema plenamente válido para la resolución de conflictos.

- Segunda. Tanto la legislación comunitaria como la nacional, así la estatal pero sobre todo la autonómica, abogan, por diversos motivos, por una seria apuesta por la mediación como medio autocompositivo de resolución de conflictos, retirando la exclusividad al sistema judicial en la resolución de conflictos en el ámbito familiar.

- Tercera. Con la mediación no se trata de instaurar una justicia alternativa en paralelo a la de los Jueces y Magistrados profesio-

${ }^{21}$ BOLDÚ Maite, y otros «Introducción a la mediación» en Mediación familiar y social en diferentes contextos op. cit. Pág. 90. 
nales, pues no hay reticencia ante el Juez profesional, de lo que se trata es de establecer un procedimiento que satisfaga un derecho-deber de los ciudadanos a participar directamente en la vida social mediante la responsabilidad de componer sus conflictos.

- Cuarta. Dos son los aspectos esenciales en los que convergen las características de la mediación, su objetivo y el modo en que este se alcanza. El objetivo último de la mediación es el acuerdo inter-partes que evita o pone fin a un litigio entre ellas, lo que singulariza ese acuerdo o su intento por alcanzarlo, es que en su consecución participa un tercero imparcial que actúa como mediador, con todo lo que ello representa, tratando de acercar las posturas enfrentadas de las partes.

- Quinta. El acuerdo o transacción es el objetivo último de la mediación, este se traduce en un acuerdo de voluntades por el que se compone la controversia entre las partes y en este sentido, aquel vendría a ser el resultado positivo de la mediación, en donde sus efectos, son los derivados del deber de cumplimiento que pueden las partes exigirse recíprocamente.

- Sexta. Como método de resolución de conflictos, la Mediación es un medio independiente, no alternativo ni siquiera complementario al sistema judicial pues una de las causas de su desarrollo es su respuesta eficaz al acceso a la justicia y su fundamento se encuentra en la libertad de decisión de los ciudadanos.

- Séptima. Debido al hecho que hasta la fecha el legislador nacional no ha promulgado legislación alguna respeto a la Mediación, y al no haber una ley de bases que establezca los márgenes de ésta institución, los legisladores autonómicos deberían ser más cuidadosos y hacer uso de una más fina técnica legislativa a la hora de regular y definir dicha institución, so riesgo de deslegitimarla desde su inicio, por crear confusión y desconfianza en su aplicación tanto para las ciudadanos como para los operadores profesionales.

\section{OBRAS Y DOCUMENTOS DE CONSULTA:}

BARONA VILAR, SILVIA, Solución extrajudicial de conflictos "Alternative Dispute Resolution» (ADR) y derecho procesal, Tirant lo Blanch, Valencia 1999. 
BERNAL SAMPER, Trinidad, La Mediación. Una solución a los conflictos de ruptura de pareja. $2^{a}$ edición Madrid, Colex, 2002

DE CASTRO CID, B. (coordinador), Problemas básicos de Filosofía del Derecho: desarrollo sistemático, $3^{a}$ edición. Madrid, Universitas, 2003

DELGADO DE MIGUEL, Juan Francisco y GARRIDO DE PALMA, Víctor M., Instituciones de Derecho Privado, Tomo IV, Familia, Vol. $1^{\circ}$ Madrid, Civitas 2001

ESCRIVA IVARS, Javier, Matrimonio y Mediación Familiar, Instituto de Ciencias para la Familia, Universidad de Navarra, Madrid Ediciones Rialp 2001

GARCÍA GARCÍA, Lucía, Mediación Familiar. Prevención y alternativa al litigio en los conflictos familiares, Madrid, Dykinson 2003

GIMENO SENDRA, Vicente, Derecho Procesal Penal, Madrid, Colex 2004.

HAYNES, JOHN M., Fundamentos de la Mediación Familiar, Madrid GAIA ediciones 1995.

LANDETE CASAS, José, «Aspectos Generales sobre la mediación y el mediador» en Revista Internauta de Práctica Jurídica, núm. 2, mayo-agosto 1999.

LASARTE ÁlVAREZ, Carlos, Principios de Derecho Civil, Tomo III, Contratos, $6^{a}$ edición, Madrid, Trivium 2001

Principios de Derecho Civil, Tomo VI, Derecho de Familia, $6^{a}$ edición, Madrid, Marcial Pons, 2007.

LORCA NAVARRETE, Antonio María y DENTICI VELASCO, Nina María, La Regulación de la Separación y el Divorcio en la nueva "Ley de Divorcio» de 2005 con especial referencia a la Mediación Familiar, San Sebastián, Instituto Vasco de Derecho Procesal, 2005.

PÉREZ DEL CAMPO, Ana María, «Origen y Transmisión de la Violencia de Género» en Violencia de Género. Una visión multidisciplinar. Centro de Estudios Ramón Areces, 2008.

POYATOS GARCÍA, Ana (coordinadora), Mediación familiar y social en diferentes contextos, Universidad de Valencia, Valencia, Nau Llibres, 2003.

ROMERO NAVARRO, Fermín, «La Mediación familiar. Un ejemplo de aplicación práctica: la comunicación a los hijos de la separación de los padres. El papel del mediador», en Revista del Ministerio de Trabajo y Asuntos Sociales, núm. 40, 2002. 
SAN SEGUNDO MANUEL, Teresa, «Las Leyes Civiles ante el maltrato» en Violencia de género. Una visión multidisciplinar, Centro de Estudios Ramón Areces, 2008.

— «Maltrato y nueva Ley de Divorcio» en Familia, matrimonio y divorcio en los albores del siglo XXI, Jornadas Internacionales sobre las Reformas del Derecho de Familia, Madrid, junio 2005. Ed. UNED-IDAFE-El Derecho.

TENA PIAZUELO, Isaac, «La mediación conyugal en la crisis matrimoniales» en Noticias Jurídicas, Artículos Doctrinales de Derecho Civil. Enero 2001.

VILLAGRASA ALCAIDE, Carlos y VALL RIUS, Ana M., "La mediación familiar: una nueva vía para gestionar los conflictos familiares» en La Ley, núm.5049, mayo 2000.

\section{LEGISLACIÓN Y JURISPRUDENCIA CONSULTADA:}

- Código Civil español.

- Constitución Española de 1978.

- Convención sobre la eliminación de todas las formas de discriminación contra la mujer, de la ONU (CEDAW), adoptada en New York el 18 de diciembre de 1979.

- Directiva 2008/52/CE, del Parlamento Europeo y del Consejo, de 21 de mayo de 2008, sobre ciertos aspectos de la mediación en asuntos civiles y mercantiles.

- Ley Orgánica 1/2004, de 28 de diciembre, de Medidas de Protección Integral contra la Violencia de Género.

- Ley Orgánica 3/2007, de 24 de marzo, para la igualdad efectiva entre mujeres y hombres.

- Ley de Enjuiciamiento Civil de 1881.

- Ley 1/2000, de 7 de enero, de Enjuiciamiento Civil.

- Ley 1/2001, de 15 de marzo, de Mediación Familiar en Cataluña.

- Ley 4/2001, de 31 de mayo, reguladora de la Mediación Familiar en Galicia.

- Ley 7/2001, de 26 de noviembre, Reguladora de la Mediación Familiar en el ámbito de la Comunidad Valenciana. 
- Ley 15/2003, de 8 de abril, de la mediación familiar en Canarias.

- Ley $13 / 2005$, de 1 de julio, por la que se modifican el Código Civil y la Ley de Enjuiciamiento Civil en materia de derecho a contraer matrimonio.

- Ley 4/2005, de 24 de mayo, del Servicio Social Especializado de Mediación Familiar de Castilla-La Mancha.

- Ley 15/2005, de 8 de julio, por la que se modifican el Código Civil y la Ley de Enjuiciamiento Civil en materia de separación y divorcio. León.

- Ley 1/2006, de 6 de abril, de mediación familiar de Castilla y Baleares.

- Ley 18/2006, de 22 de noviembre, de Mediación Familiar de

- Ley 1/2007, de 21 de febrero, de Mediación Familiar de la Comunidad de Madrid.

- Ley del Principado de Asturias 3/2007, de 23 de marzo, de Mediación Familiar. Vasco.

- Ley 1/2008, de 8 de febrero, de Mediación familiar del País

- Ley 1/2009, de 27 de febrero, reguladora de la Mediación Familiar en la Comunidad Autónoma de Andalucía.

- Libro Verde sobre las modalidades alternativas de solución de conflictos en el ámbito del derecho civil y mercantil (presentado por la Comisión) COM (2002) 196 final.

- Propuesta de Directiva del Parlamento Europeo y del Consejo sobre ciertos aspectos de la mediación en asuntos civiles y mercantiles.COM /2004) 718 final.

- Protocolo para la implantación de la Mediación Familiar intrajudicial en los Juzgados y Tribunales que conocen de procesos de familia, del Consejo General del Poder Judicial, mayo 2008.

- Recomendación $\mathrm{N}^{\circ} \mathrm{R}$ (98) 1 del Comité de Ministros a los Estados miembros sobre la mediación familiar.

- Recomendación 12/86 del Comité de Ministros del Consejo de Europa relativa a las medidas tendentes a prevenir y reducir la sobrecarga de trabajo de los Tribunales de Justicia. 
- Reglamento (CE) No 2201/2003 del Consejo, de 27 de noviembre, relativo a la competencia, reconocimiento y la ejecución de resoluciones judiciales en materia matrimonial y de responsabilidad parental.

- STS de 27 de noviembre de 1987. Ponente: Gumersindo Burgos Pérez de Andrade.

\section{ABREVIATURAS:}

ADR (en inglés) Resolución alternativa de conflictos

Art. Artículo.

CC. Código Civil.

CGPJ Consejo General del Poder Judicial.

LEC Ley de Enjuiciamiento Civil

LO Ley Orgánica.

LOPJ Ley Orgánica del Poder Judicial. 
06-Darriba 13/04/2011 12:42 Página 230 